This article was downloaded by:[Hopayian, Kevork]

On: 19 January 2008

Access Details: [subscription number 789474583]

Publisher: Informa Healthcare

Informa Ltd Registered in England and Wales Registered Number: 1072954

Registered office: Mortimer House, 37-41 Mortimer Street, London W1T 3JH, UK

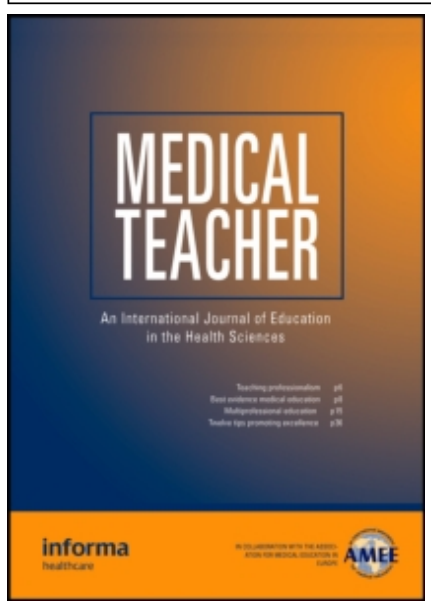

\title{
Medical Teacher
}

Publication details, including instructions for authors and subscription information: http://www.informaworld.com/smpp/title content=t713438241

A survey of UK medical schools' arrangements for early patient contact

Kevork Hopayian a; Amanda Howe ${ }^{a}$; Valerie Dagley ${ }^{a}$

a School of Medicine, Health Policy and Practice, University of East Anglia, Norwich

First Published on: 29 November 2007

To cite this Article: Hopayian, Kevork, Howe, Amanda and Dagley, Valerie (2007) 'A

survey of UK medical schools' arrangements for early patient contact', Medical

Teacher, 29:8, $806-813$

To link to this article: DOI: $10.1080 / 01421590701543125$

URL: http://dx.doi.org/10.1080/01421590701543125

\section{PLEASE SCROLL DOWN FOR ARTICLE}

Full terms and conditions of use: http://www.informaworld.com/terms-and-conditions-of-access.pdf

This article maybe used for research, teaching and private study purposes. Any substantial or systematic reproduction, re-distribution, re-selling, loan or sub-licensing, systematic supply or distribution in any form to anyone is expressly forbidden.

The publisher does not give any warranty express or implied or make any representation that the contents will be complete or accurate or up to date. The accuracy of any instructions, formulae and drug doses should be independently verified with primary sources. The publisher shall not be liable for any loss, actions, claims, proceedings, demand or costs or damages whatsoever or howsoever caused arising directly or indirectly in connection with or arising out of the use of this material. 


\title{
A survey of UK medical schools' arrangements for early patient contact
}

\author{
KEVORK HOPAYIAN, AMANDA HOWE \& VALERIE DAGLEY \\ School of Medicine, Health Policy and Practice, University of East Anglia, Norwich
}

\begin{abstract}
Background: Many U.K. medical schools have patient contact in the first two years of the undergraduate course.

Aim: To compare the purposes and organization of early patient contact in UK medical schools and to relate these arrangements to the schools' curricular objectives.

Methods: A telephone survey of lead educators in UK medicals schools. Categories of contact were plotted against phases of the course to discern patterns of organisation.

Results: The quantity of contact varies considerably (four to 65 days). There is a pattern, with learning objectives around the social context of health and illness preceding skills based work and integrated clinical knowledge for practice coming later. Schools fall into three categories: close adherence to the preclinical/clinical split, with limited early contact acting as an introduction to social aspects of health; provision of substantial patient contact to maximize the integration of knowledge and skills; and transitional, with limited clinical goals. General practice provides between one third and one half of early patient contact.

Conclusions: Arrangements meet the objectives set by each school and reflect differing educational philosophies. Change is toward more early contact. There appears to be no national guidance which supports a minimum quantity of patient contact or specific educational purpose in the early years of U.K. basic medical training.
\end{abstract}

\section{Introduction}

The General Medical Council's 'Tomorrow's Doctors' recommended that medical training should achieve a patient-oriented doctor familiar with the perspectives and life context of the public. To this end it recommended that patient contact should start earlier in training and make more use of primary care and community settings (General Medical Council 1993). Early patient contact (EPC) is here defined as patient contact within the first two 'preclinical' years of basic training (Littlewood et al. 2005). The advocates of EPC claim that it supports an integrated curriculum (West et al. 1982; Cade 1993); encourages a patient-centred approach (Nathanson et al. 1987; Lassen et al. 1989; Cade 1993; Valkova 1997); improves communications skills (Lassen et al. 1989; Cade 1993; Valkova 1997) and reinforces students' motivation towards their career choice (Vieira et al. 2003; McLean 2004).

EPC is appreciated by students (Friedberg \& Glick 1997; Johnson \& Scott 1998; Vieira et al. 2003) and valued by staff (Friedberg \& Glick 1997; Johnson \& Scott 1998). Comparing outcomes in performance has been problematic due to small sample sizes (Pamies et al. 1994) and the difficulties of longitudinal follow up (Dahle et al. 1997). A recent systematic review concluded that it 'helps medical students learn, helps them develop appropriate attitudes towards their studies and future practice, and orientates medical curricula towards society's needs' (Littlewood et al. 2005). However, this review may not convince EPC's critics, as it drew more on descriptive than comparative studies, and made causal inferences mainly

\section{Practice points}

- There is considerable variation in the arrangements for EPC, reflecting differing educational philosophies.

- A few medical schools have substantial EPC, aiding the progress towards many of these clinical objectives early in the course.

- Substantial early patient contact is destined to become more widely employed in UK medical schools.

from qualitative studies which, arguably, are not designed for such purposes

EPC has often accompanied a shift towards community based education, in which both students (Howe 2001) and GPs have been pleased with their new role (Haffling et al. 2001). A number of studies have shown significant positive impacts of community based training (Murray et al. 1997; Hampshire 1998; Worley et al. 2000), though some of these have focused on the later years of training, and few have been able to say whether it is the timing, the patient contact, or the learning environment that has led to these benefits. The logistics and workload of organizing patient contact have been mentioned as a major potential barrier to both EPC and community based learning (Wilson et al. 1996; Gray \& Fine 1997; Carney et al. 1999). Perhaps surprisingly, however, there is no recent study to show what actual patient contact is being provided in the early years of UK medical training, nor the extent to which this is based in, or delivered by, general practice.

Correspondence: Dr. Kevork Hopayian, Seahills, Leiston Road, Aldeburgh IP15 5PL, England. Tel: 01728 454918; fax: 01728 832029; email: k.hopayian@btinternet.com 
Aims

The present study arose out of an evaluation of patient contact in the first year of the new medical curriculum at the University of East Anglia. In order to put into context our arrangements for EPC, we investigated arrangements in other medical schools in the United Kingdom. This study aims to describe when students have first contact with patients, how such contact is organized, how these arrangements relate to the curricular objectives, and the amount of EPC provided in general practice.

\section{Method}

A survey in medical schools in the United Kingdom was conducted through either the Dean or the lead person for each course, such as the Course Director or Director of Medical Education, depending on the school's preference. Initial contacts were identified from the contact list provided by the Association for the Study of Medical Education (ASME). Contacts for schools not included on the ASME list were found on lists on the internet (British Medical Association 2005; Medical Protection Society 2005). The survey took place between October 2004 and June 2005.

The experience of the authors and the relevant literature suggested that patient contact has different dimensions-time, place, purpose, planned or opportunistic. We developed an interview protocol with questions to cover each of these dimensions (Table 1). The interview schedule was piloted with two senior medical educationalists not included in the main data collection.

Interviews were conducted on the telephone by one researcher $(\mathrm{KH})$. Interviewees were given advance information about the purpose and factual content so they could prepare any details needed. The interviewing style was naturalistic, employing open-ended questions followed by closed questions to clarify points, obtain examples and to ensure that all the questions had been answered. Gaps in information were supplemented from any other informant suggested by the interviewee, or from the schools' prospectuses on the web.

\section{Treatment of medical schools with differing entry arrangements}

Thirty one medical schools were identified. We treated those schools that act as 'feeders' for the clinical phase of others as separate schools, since they make their own arrangements for the early phase of the course. For medical schools that had both undergraduate and graduate level of entry with differing arrangements, only the undergraduate arrangements were used.

\section{Analysis}

The interviewer took field notes during the interviews and entered them into a database containing a field for each interview item. For descriptive items, such as the form of contact (item 3), the interviewer compared field contents between records and coded them. The process continued
Table 1. Checklist of items used by interviewer in semi-structured telephone interview.

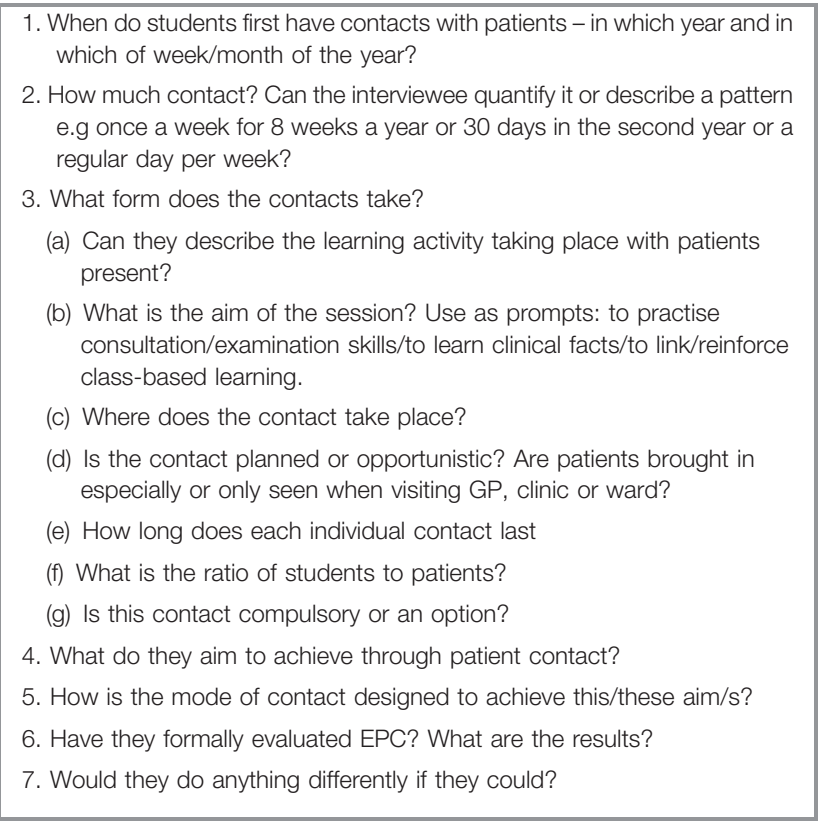

until no new codes were produced. The item in each record was allocated one or more codes. The codes were validated by an independent reading of the records by a second researcher (VD).

The method of calculation of amount of contact depended on how the information was provided by the interviewee. Where interviewees were able to state categorically the number of days in a given period, the data were taken as given. Interviewees who reported contact time in 'sessions' were asked to define the length of a session. The hours were summed into whole days for reporting findings.

A summary of each interview was sent to the interviewee for clarification and correction. This allowed interviewees to check that the description of purposes and arrangements were accurately reported and to check the accuracy of our calculations.

\section{Results}

\section{Response rate}

Twenty eight interviews were conducted (response rate 90\%). Eighteen out of the 28 returned confirmed interview summaries.

\section{Timing and quantity of contact}

Most medical schools (24) have patient contact by the end of the first trimester, eight by the end of the first week and three start on the first day. All schools have introduced patient contact in the first year, though some do not do so until towards the end of that year.

The amount of time students spend with patients varies widely, from four whole day equivalents (WDEs) to 65 in years 
Table 2. Quantity of early patient contact.

\begin{tabular}{|c|c|c|c|c|}
\hline & No. days in year 1 & No. days in year 2 & $\begin{array}{l}\text { Total no. days } \\
\text { in years } 1 \text { and } 2\end{array}$ & $\begin{array}{l}\text { Total no. days spent } \\
\text { in general practice }\end{array}$ \\
\hline Median & 9 & 13.5 & 23 & 8 \\
\hline $\begin{array}{l}\text { Range } \\
\text { (minimum, } \\
\text { maximum }\end{array}$ & $1.5-20$ & $1.5-56$ & $4-65$ & $1.5-37.5$ \\
\hline Inter-quartile range & $4-15$ & $6-20$ & $16-31$ & $12-31.75$ \\
\hline
\end{tabular}

1 and 2 combined (Table 2). However, the number of WDEs is not itself a measure of effort put into teaching and learning from patient contact, nor can this be used to judge learning impacts. For example, one school that has only two WDEs in year 1, distributed over four weeks, but sets aside considerable time in preparation and follow through after the contacts. Others have substantive pieces of assessed coursework based on such contacts (Hannay et al. 2003).

\section{Community location}

A considerable number of EPC days are provided by general practitioners (Table 2). The proportion of EPC located in general practice was between $33 \%$ and $53 \%$ in half the medical schools.

\section{Medical schools' objectives}

Most learning activities fulfil more than one objective, and interviewees offered several objectives for patient contact. We distinguished two sets of objectives: 'learning' and 'pedagogic' (Table 3). The learning objectives apply to all stages of the curriculum; the pedagogic objectives are specific to EPC and provide the rationale for it.

\section{Pedagogic objectives}

Reinforcing class room teaching. This is particularly important for those schools with integrated curricula where real patients 'bring to life' case based or problem based learning. However, this objective was not confined to them. An interviewee in a school with a traditional course and limited exposure also believed that learning was more effective if linked with patients:

very important early in course because students learn best in context.

Linking basic medical science and clinical care. This is a fundamental principle for those schools that have vertical, fully integrated science and clinical teaching. However, other schools, including those with only brief EPC, also believe that they achieve this. Linkage works in two directions: making the science relevant and interesting while fostering professional attitudes during scientific training:

To provide a scientific approach to medicine while being humanistic.
Table 3. Aims and purposes of early patient contact emerging from interviews.

Learning objectives

1. Understanding the patient experience and perspective of disease and health care.

2. Understanding the social context of illness: the social determinants of health and the impact of disease on families and society.

3. The acquisition of communication skills and professional attitudes in relationships with patients.

4. The acquisition of clinical skills: history taking and clinical examination.

5. The acquisition of core clinical knowledge: learning about disease, diagnosis, and management.

6. Understanding health service organisation: health service delivery and inter-professional relationships.

7. Prequalification experience in preparation for work.

Pedagogic objectives

1. To reinforce class room teaching

2. To link basic medical science to patient care

3. To provide a future focus for the ultimate objective of patient care.

Future focus. Some interviewees stressed the importance of providing a focus for the vocation for which they are training:

Above all to motivate students - they come to study to be doctors.

A few schools reported negative outcomes of EPC: for example, some schools that have a more traditional preclinical/clinical split have given students a limited introduction to elementary clinical skills such as measuring blood pressure, but the scope of early contact may be limited by lack of educational support for its impacts. One school described abandoning its experiments with teaching complex clinical skills in earlier years because it found that students had forgotten these after a subsequent year of entirely theoretical instruction.

\section{Varying arrangements to meeting learning objectives and pedagogic objectives}

EPC arrangements for each objective vary between schools. Table 4 shows paired examples of schools with differing arrangements to meet the same objectives. The variation in timing and arrangements reflects in part different educational philosophies and different circumstances. The interviewee from one school that has 44 WDEs of substantial early contact 
Table 4. Examples of objectives of early patient contact matched to arrangements.

\begin{tabular}{|c|c|c|c|}
\hline Objectives & $\begin{array}{l}\text { Medical } \\
\text { school }\end{array}$ & Related period & Arrangements \\
\hline \multirow[t]{2}{*}{$\begin{array}{l}\text { Link basic medical science } \\
\text { to clinical medicine }\end{array}$} & 24 & $\begin{array}{l}\text { From Semester } 1 \\
\text { Year } 1 \text { and to } \\
\text { end of Year } 2\end{array}$ & $\begin{array}{l}\text { Systems based teaching. A clinician presents a clinical scenario in the } \\
\text { auditorium theatre to all } 400 \text { students who then study the related } \\
\text { basic medical science in the ensuing week. Integration occurs at the } \\
\text { end of the week by discussing the case again. The week of study } \\
\text { may involve seeing a patient. }\end{array}$ \\
\hline & 31 & $\begin{array}{l}\text { From Semester } 1 \\
\quad \text { Year } 1\end{array}$ & $\begin{array}{l}\text { Problem based learning starts with introduction of problem at beginning } \\
\text { of week. Students study both medical science and clinical medicine. } \\
\text { Integration at the end of the week. Study during the week includes } \\
\text { one day seeing patients, in primary or secondary care. }\end{array}$ \\
\hline Clinical skills & 2 & $\begin{array}{l}\text { From Semester } 1 \\
\quad \text { Year } 1\end{array}$ & $\begin{array}{l}\text { Clerk patients under supervision from the first year and have substantial } \\
\text { contact ( } 15 \text { days in year } 1) \text {. }\end{array}$ \\
\hline Communications skills & 29 & $\begin{array}{l}\text { From Semester } 1 \\
\quad \text { Year } 1\end{array}$ & $\begin{array}{l}\text { Interactive demonstration in lecture theatre with approximately } 250 \\
\text { students. The teacher demonstrates history taking, symptoms, } \\
\text { malfunction, questioning styles, and doctor-patient interaction. The } \\
\text { students complete a work sheet, introducing them to the elements of } \\
\text { history taking. From the second semester of year 2, the students are } \\
\text { attached to teams where they learn clinical examination. }\end{array}$ \\
\hline \multirow[t]{2}{*}{ Patient experience } & 20 & $\begin{array}{l}\text { From Semester } 1 \\
\text { Year } 1 \text { to end } \\
\text { Year } 2\end{array}$ & $\begin{array}{l}\text { An hour long self-presentation by a patient with chronic disease to the } \\
\text { class of } 95 \text { students. The patient is joined by his/her health care } \\
\text { practitioner (not necessarily a doctor). Personal issues are explored } \\
\text { including the impact of illness on his/her own life and his/her } \\
\text { perception of the quality of that life. }\end{array}$ \\
\hline & 25 & $\begin{array}{l}\text { From Semester } 1 \\
\text { Year } 1 \text { to end } \\
\text { Year } 2\end{array}$ & $\begin{array}{l}\text { Students are carefully briefed on discussing patients' health problems, } \\
\text { their experience and their expectations of health care. They write a } \\
\text { structured report, designed to encourage reflection, of their interview. }\end{array}$ \\
\hline \multirow[t]{2}{*}{$\begin{array}{l}\text { Reinforce class room } \\
\text { teaching }\end{array}$} & 17 & $\begin{array}{l}\text { From Semester } 1 \\
\quad \text { Year } 1\end{array}$ & $\begin{array}{l}\text { During their hospital attachments, students are expected to record } \\
\text { "trigger cases", conditions relevant to the concurrent problem based } \\
\text { learning topic. They are common conditions which are likely to be } \\
\text { encountered on the wards or in outpatients and are important to } \\
\text { learn. }\end{array}$ \\
\hline & 31 & $\begin{array}{l}\text { From Semester } 1 \\
\quad \text { Year } 1\end{array}$ & $\begin{array}{l}\text { Co-ordination with clinical teachers so that selected patients match the } \\
\text { concurrent topic in problem based learning. }\end{array}$ \\
\hline \multirow{2}{*}{$\begin{array}{l}\text { Health service delivery and } \\
\text { inter-professional } \\
\text { relationships }\end{array}$} & 11 & Semester 2 Year 2 & Use of specialist clinical teachers, usually nurses, to teach clinical skills \\
\hline & 4 & $\begin{array}{l}\text { From Semester } 1 \\
\quad \text { Year } 1\end{array}$ & $\begin{array}{l}\text { Students spend two half days each month observing in a variety of } \\
\text { clinical settings, such as physiotherapy. In Year 2, there is a one } \\
\text { week nursing attachment. }\end{array}$ \\
\hline
\end{tabular}

explained that the arrangement stemmed from a belief in the complete integration of theory and practice, basic medical sciences and clinical approaches, clinical knowledge with communications skills' and '(the) conviction that teaching is more effective through problem based learning and should be in the community where the burden of disease lies and where the approach is broader and more rounded.' At another school, where there are eight whole day equivalents in the preclinical phase, EPC is restricted to interviewing patients, followed by a report and an introduction to simple clinical skills. The aim is to 'contextualize learning' rather than cover clinical objectives.

In clinical teaching, three schools invite patients specifically to link with concurrent theoretical teaching, in order to situate learning in the context of patient care (Seely Brown et al. 1989) They also include the use of 'expert patients' and 'standardised patients', patients with the chosen disorder but who have been coached in their role. Other, looser approaches to matching classroom and bedside teaching include a list of 'target conditions' students are encouraged to find and report on during their clinical attachments. GPs' disease registers for identifying suitable patients are made use of by several schools.
Resources, pressure on time and other curricular considerations also influence arrangements. For example, a learning objective on the views and experience of an expectant mother during study of the life cycle could vary from a single episode to an extended relationship over months, and some schools altered such attachments to fit in with patient availability without noticing any loss of learning.

Most medical schools collect student and staff opinions on early patient contact as part of their routine annual curriculum evaluation. The unanimous finding reported, regardless of specific arrangements, is that students find EPC beneficial.

\section{Patterns of patient contact}

All medical schools cover the seven learning objectives by the end of their courses: these are inclusive categories which describe the purposes of patient contact. The amount and purpose of patient contact built up over time appeared to follow a pattern, with learning objectives around the social context of health and illness preceding skills based work, and integrated clinical knowledge for practice coming later. 


\section{Table 5. Categories of patient contact grouped by aim and activity.}

\begin{tabular}{|c|c|c|}
\hline Contact & Aim & Activity \\
\hline I & $\begin{array}{l}\text { To gain familiarity with meeting people and to } \\
\text { appreciate the determinants of health. }\end{array}$ & $\begin{array}{l}\text { Students may meet patients or people who may not be receiving medical care but who } \\
\text { are seen in a health related context. (i) students observe and follow-up individuals or } \\
\text { families in the community, often in a normal part of the life cycle such as families with } \\
\text { a newborn. (ii) students observe social care agencies such as drug rehabilitation } \\
\text { centres. }\end{array}$ \\
\hline$\|$ & $\begin{array}{l}\text { As for (I) but also to gain communication skills } \\
\text { and to understand the patient's experience. }\end{array}$ & $\begin{array}{l}\text { Students meet and communicate with patients with disorders but the emphasis is on } \\
\text { communicating and understanding the person's experience of the illness, the } \\
\text { implications of the illness on the person's life, and the patient's experience of the } \\
\text { health service rather than on learning about systems or the disorders. }\end{array}$ \\
\hline III & $\begin{array}{l}\text { As for (II) but also to begin to learn clinical skills } \\
\text { namely history taking and examination. }\end{array}$ & $\begin{array}{l}\text { Observation of a clinician at first followed later by practical history taking and } \\
\text { examination. }\end{array}$ \\
\hline IV & $\begin{array}{l}\text { As for (III) and in addition to learn core clinical } \\
\text { knowledge and to learn clinical skills. }\end{array}$ & $\begin{array}{l}\text { Supplementing theoretical knowledge gained in the class room with contact with } \\
\text { patients. }\end{array}$ \\
\hline
\end{tabular}

To test this impression, we compared four periods in the programme: the first three months, when most schools initiate some form of early contact; the rest of year one; year two; and after year two (by definition, no longer EPC). The seven types of learning objective for patient contact were grouped into four overall categories (Lincoln \& Guba 1985) according to the aims of the contact and the types of activity associated with it (Table 5). Group I incorporates the learning objective of the social context of illness; group II, communications skills and the patient experience; group III, clinical skills; and group IV, integrating core knowledge and skills and gaining experience.

On reviewing the data, we found that understanding the patient experience and communication skills are almost always taught closely, so we combined these. We drew a grid of the four periods and the four categories. We plotted the timing and category for each medical school into the grid.

Three patterns of patient contact emerged (Figure 1). Pattern 3, which we refer to as providing substantial early patient contact, introduces all four forms of contact within the first year if not the first trimester. All schools following pattern 3 tended to integrate their scientific and clinical learning, and to be in the new wave of medical schools in the UK (that is, established in the last five years). Pattern 1, which we refer to as adhering more to the traditional preclinical/ clinical split, has a more delayed introduction of contact categories II to IV. There is an intermediate pattern in which, regardless of the preclinical/clinical split, contact categories II to III are introduced at variable times within the first two years.

\section{General practitioners' contribution}

GPs in twenty five out of the twenty eight schools contributed specifically in teaching towards the first three learning objectives in Table 3; namely, understanding the patient perspective, understanding their social context, and acquiring communications skills. Some schools chose general practice as the main location for the teaching of these psychosocial aspects of medicine. In nine medical schools, formal teaching of clinical skills also took place in general practice. Four of these schools adhered to the substantial early contact pattern.

\section{Changes in the curriculum}

Two medical schools had recently changed their curricula and four were planning to do so. Changes included further vertical integration and more early patient contact.

Six interviewees, including two with pattern 3, would like more EPC. Six interviewees want more EPC in general practice and two want more in hospitals. Four interviewees want more integration of basic and clinical science. They reported two constraints to their desired changes: the lack of resources to employ more tutors and the logistics of co-ordinating hundreds of students, several hospitals and several general practices.

Two interviewees stand out in arguing that curricular reform, including EPC and the early introduction of communication skills teaching, has resulted in the loss of the learning through practical experience that the former apprenticeship system offered, whereby students '... learn skills and knowledge while contributing to work of the firm in giving patient care rather than being a spectator'. These interviewees suggested the revival of the 'student locum' in the final year as a solution.

\section{Discussion}

\section{Summary of main findings}

This survey describes the current state of EPC in UK medical schools. All medical schools share the same ultimate learning objectives and a commitment to EPC, congruent with their accreditation by the GMC, with general practice making a substantial contribution in many cases. Therefore, the striking variation in the amount of patient contact in the curriculum, ranging from as few as 4 to as many as 65 WDEs in the first two years, deserves attention. However, quantity alone does not provide a sufficient basis for comparison. There is also a rich variation in arrangements such as in teaching and learning activities, the degree of structuring of contact, and the balance between primary and secondary care. How EPC contributes to the ultimate learning objectives of the undergraduate curriculum is best understood in the totality of these features and the staging of the objectives. When all features of patient contact are considered together, it becomes apparent that each school has made arrangements to match the outcomes it 


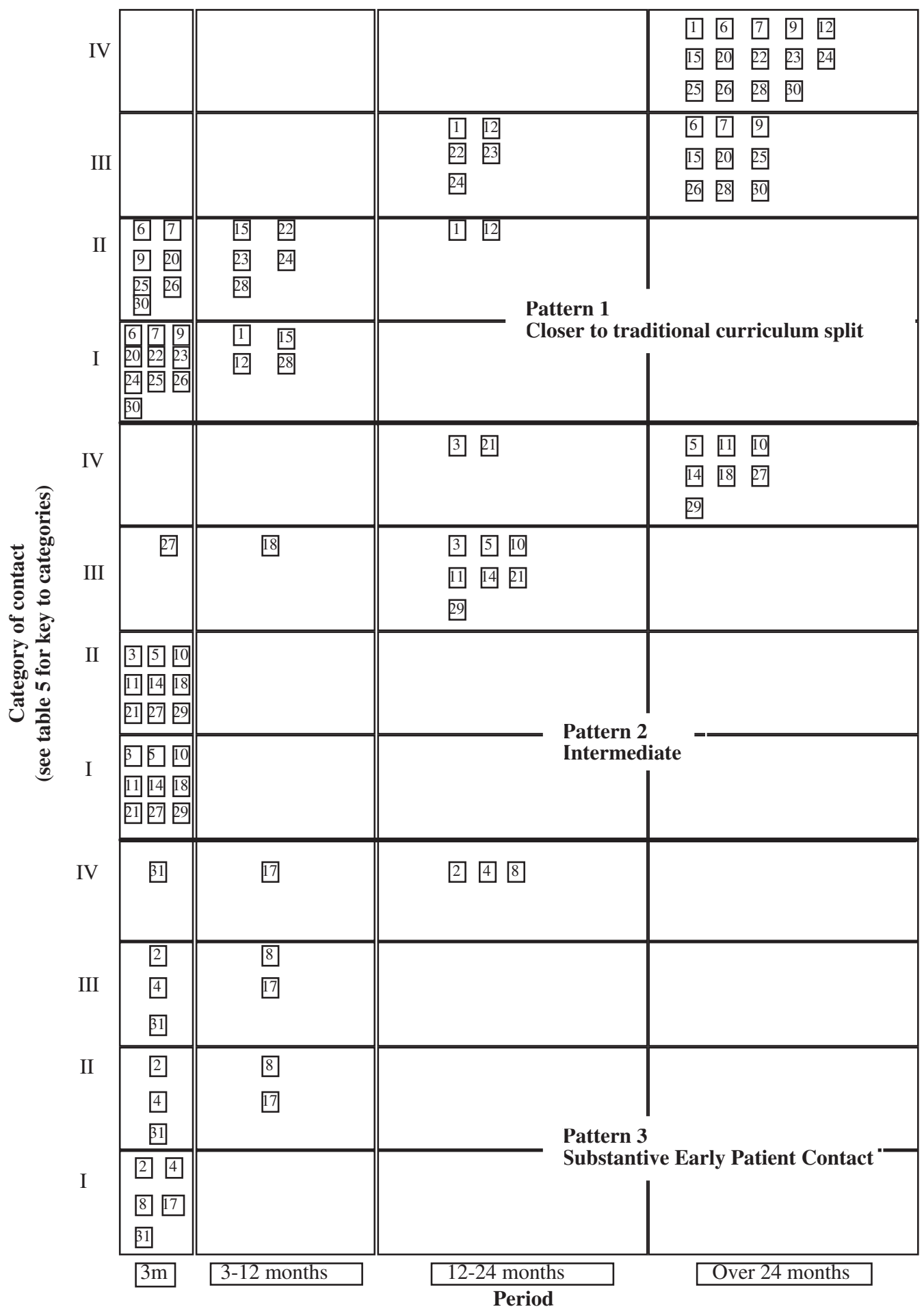

Figure 1. Categories of patient contact and period in which they commence. Numbers in boxes refer to identity number of school.

has set for different stages in the curriculum. The differences in learning outcomes set for early contact, as opposed to ultimate objectives, appear to play a large part in the variation in timing and arrangements for EPC. We have suggested that three patterns of EPC can be discerned. We suggest that these patterns reflect differing educational philosophies or strategies.

A few schools (pattern 3) subscribe to substantial, early patient contact in hospital and in the community. The educational philosophy which underpins this strategy includes beliefs in vertical integration and patient-centred, community based education from the start. In contrast, some schools (pattern 1) limit EPC to an introduction to patient-centredness and community issues that may be more fully developed later when specific clinical knowledge and skills are taught. The educational philosophy which underpins this strategy maintains a clear preclinical/clinical split in the curriculum. However, many schools have an intermediate pattern and may be more eclectic in their philosophies and strategies. The ways 
in which different settings are used to achieve specific objectives is rarely specified. Our survey shows that one GMC objective has been met with GPs making a substantial contribution to EPC. Although the data regarding GPs' specific contribution was limited in this survey, it appears that it is most commonly to address psychosocial issues rather than the full range of clinical practice.

\section{Strengths and the limitations of this study}

The strength of our study is that the information came from a significant informant, whose central role in the curriculum of each medical school lends credibility to its accuracy. Reliance on a sole informant raises the issue of personal bias, but the interview protocol attempted to minimise this with its quasi - factual approach, and opinion was only encouraged in the section addressing desires for change.

Calculating the quantity of contact may have led to inaccuracies, but there is no reason to suspect bias towards either over or under-estimating, and the interview reports were fed back. Interpretation of the grid plot involves a degree of subjectivity. We offer the plots to readers for scrutiny to check our interpretation.

Interestingly, very few informants made specific comments about GP based teaching being different from other settings in terms of its purpose and proposed outcomes. This may reflect the interview protocol, which did not aim to elicit interdisciplinary differences. It may also mean that GP has 'come of age' as a teaching and learning setting, and is included as one of many health service settings where patients can be located. It was clear from the data, however, that general practices were extensively involved in early patient contact, including skills learning, and the general will towards increased EPC has implications for GP tutors just as it does for hospital staff.

\section{Implications for clinical practice and future research}

Curriculum planners may find it useful to look at Figure 1 to see where they would place themselves in the continuum and whether their curricular arrangements for EPC are suited to their stage-specific objectives. The answer to this last question would be better informed if we had more and better evidence. We do not know how well current arrangements deliver outcomes set for particular stages in the course. For example, do specially invited patients compared to patients seen during routine clinical care add value to learning? Nor do we know which arrangements deliver better ultimate outcomes. Strategies currently based on convictions may be better informed in future by the synthesis of research evidence on medical education, a synthesis now under way (Best Evidence Medical Education 2005).

Similarly, curriculum planners may need to give more detailed attention to which clinical settings they utilise for each learning objective. Expanding EPC, especially in the context of further expansion in medical school numbers, has considerable cost and logistics implications for primary care and secondary care, and the evidence base for the best use of EPC in different settings therefore becomes vital.
Recent, planned or desired changes in the curricula uncovered by our survey have been in the direction of more patient contact, more integration and more community based teaching. It seems, therefore, that substantial early patient contact is destined to become more widely employed in UK medical schools. The variety of arrangements in existence points to the need for, and at the same time provides, the material for non-experimental, comparative research. This research would have the aim of identifying which methods of EPC most effectively deliver our shared learning outcomes.

\section{Acknowledgements}

We thank all the respondents from the following medical schools for generously giving their time to this survey: Aberdeen, Birmingham, Brighton and Sussex Medical School, Cambridge, Dundee, Durham, Edinburgh, Glasgow, Hull and York, Keele, Leeds, Leicester and Warwick, Liverpool, London St Bartholomew's, London Guy's, King's and St Thomas', London Imperial, London Royal Free and UCL, Manchester, Newcastle, Oxford, Peninsula Medical School, Queen's Medical Centre, Nottingham, Queens, Belfast, Sheffield, Southampton, St Andrews, Swansea, and the University of East Anglia.

The survey was conducted as part of an evaluation of undergraduate teaching of musculoskeletal medicine by the Primary Care Group, School of Medicine, University of East Anglia. We thank the project team, particularly Prof. Sam Leinster and Prof. David Scott, for helpful comments during the design of the study. We thank Ann Gittos, research assistant, for support in data acquisition.

The programme of which this survey formed part was funded by the Arthritis Research Campaign, to which we extend our gratitude. Reports of the whole study are obtainable from Amanda.howe@uea.ac.uk.

\section{Notes on contributors}

KEVORK HOPAYIAN is a GP in Leiston, Suffolk, Primary Care Educator in Suffolk and Honorary Senior Lecturer at the University of East Anglia. His interests include evidence-based practice and musculoskeletal medicine. AMANDA HOWE is the Professor of Primary Care and MB/BS Course at the School of Medicine, Health Policy and Practice at the University of East Anglia in Norwich, UK. She is a Consultant in Primary Care to Norfolk Primary Care Trust and holds a sessional GP post. Her research interests include mental health in primary care, professional development and medical education.

VAL DAGLEY is a Research Associate at the School of Medical, Health Policy and Practice at the University of East Anglia and was former deputy head and and Vice-Principal of Cromer High School, Norfolk. Her research interests include medical education.

\section{References}

Best Evidence Medical Education. 2005. What is BEME? Retrieved October 13, 2005 from http://www.bemecollaboration.org

British Medical Association. 2005. Becoming a doctor: UK medical schools contact. Retrieved October 13, 2005 from http://www.bma.org.uk/ ap.nsf/Content/BecomingDoctorMedSchool

Cade J. 1993. An evaluation of early patient contact for medical students. Med Educ 27:205-210. 
Carney PA, Bar-on ME, Grayson MS, Klein M, Cochran N, Eliassen MS, Gambert SR, Gupta KL, Labrecque MC, Munson PL, Nierenberg DW, O'Donnell JF, Whitehurst-Cook M, Willett RM. 1999. The impact of early clinical training in medical education: a multi-institutional assessment. Acad Med 74:S59-66.

Dahle LO, Forsberg P, Svanberg-Hard H, Wyon Y, Hammar M. 1997. Problem-based medical education: development of a theoretical foundation and a science-based professional attitude. Med Educ 31:416-424.

Friedberg M, Glick SM. 1997. Graduates' perspective of early clinical exposure. Educ Health 10:205-211.

General Medical Council. 1993. Tomorrow's doctors: Recommendations on Undergraduate Medical Education (London, GMC).

Gray J, Fine B. 1997. General practitioner teaching in the community: a study of their teaching experience and interest in undergraduate teaching in the future. Brit J Gen Pract 47:623-626.

Haffling AC, Hakansson A, Hagander B. 2001. Early patient contact in primary care: a new challenge. Med Educ 35:901-908.

Hampshire A. 1998. Providing early clinical experience in primary care. Med Educ 32:495-501.

Hannay D, Mitchell C, Cheung Chung M. 2003. The development and evaluation of a community attachment scheme for first year medical students. Med Teach 25:161-166.

Howe A. 2001. Patient-centred medicine through student-centred teaching - a student perspective on the key impacts of communitybased learning in undergraduate medical education. Med Educ 35:666-672.

Johnson AK, Scott CS. 1998. Relationship between early clinical exposure and first-year students' attitudes toward medical education. Acad Med 73:430-432.

Lassen LC, Larsen JH, Almind G, Backer P. 1989. Medical students experience early patient contact in general practice. A description and evaluation of a new course in the medical curriculum. Scandinavian J Primary Health Care 7:53-55.
Lincoln YS, Guba EG. 1985. Naturalistic Enquiry (Thousand Oaks, California, Sage).

Littlewood S, Ypinazar V, Margolis SA, Scherpbier A, Spencer J, Dornan T. 2005. Early practical experience and the social responsiveness of clinical education: systematic review. Brit Med J 331:387-391.

McLean M. 2004. Sometimes we do get it right! Early clinical contact is a rewarding experience. Educ Health 17:42-52.

Medical Protection Society. Medical Schools. 2005 Retrieved October 13, 2005 from http://www.medicalprotection.org/medical/united_kingdom/ Useful_Links/Medical_Schools.aspx

Murray E, Jolly B, Modell M. 1997. Can students learn clinical method in general practice? A randomised crossover trial based on objective structured clinical examinations. Brit Med J 315:920-923.

Nathanson L, Backer K, Long L. 1987. A first-year medical school pilot program for early clinical exposure. J Cancer Educ 2:107-11.

Pamies RJ, Herold AH, Roetzheim RG, Woodard LJ, Micceri T. 1994. Does early clinical exposure enhance performance during third-year clerkship? J Nat Med Assoc 86:594-596.

Seely Brown J, Collins A, Duguid P. 1989. Situated cognition and the culture of learning. Educ Researcher 41:32-41.

Valkova L. 1997. First early patient contact for medical students in Prague. Family Pract 14:394-396.

Vieira JE, do Patrocinio Tenorio Nunes M, de Arruda Martins M. 2003. Directing student response to early patient contact by questionnaire. Med Educ 37:119-125.

West M, Mennin SP, Kaufman A, Galey W. 1982. Medical students' attitudes toward basic sciences: influence of a primary care curriculum. Med Educ 16:188-191.

Wilson A, Fraser R, McKinley RK, Preston-Whyte E, Wynn A. 1996. Undergraduate teaching in the community: can general practice deliver? Brit J General Pract 46:457-460.

Worley P, Silagy C, Prideau D, Newble D, Jones A. 2000. The Parallel Rural Community Curriculum: an integrated clinical curriculum based in rural general practice. Med Educ 34:558-565. 